\title{
MENGGALI POTENSI PERMAINAN ANAK TRADISIONAL UNTUK MENINGKATKAN EKONOMI MASYARAKAT LOKAL BERBASIS DESA WISATA
}

\author{
Surya Hendra Saputra ${ }^{1)}$, Tri Wardoyo ${ }^{2)}$ \\ 1,2 Fakultas Teknik, Universitas Bhayangkara Surabaya \\ Email: ${ }^{1}$ surya.hendra.saputra48@gmail.com,triwardoyo_ubhara@yahoo.co.id ${ }^{2}$
}

\begin{abstract}
Abstrak
Kuliah kerja nyata sebuah pengabdian di desa yang kami lakukan berada di Desa Pagerngumbuk Kecamatan Wonoayu. Lokasi yang sangat tepat untuk menunjang kegiatan KKN kami untuk mengembangkan potensi Desa tersebut. Dengan adanya potensi tersembunyi di desa tersebut kami akan menggali lebih potensi desa dengan cara mensosialisasikan permainan tradisional kepada anak-anak warga desa tersebut. Dengan adanya permainan tradisional, desa ini akan menjadi desa wisata dengan konsep pengembangan pola pikir anak-anak, disampingi itu juga bisa mengembangkan perekonomian warga lokal. Dengan melakukan penyuluhan, pelatihan, dan sosialisasi tentang potensi desa wisata. kami mengajak warga desa lebih aktif dan lebih sadar akan potensi desa yang dimiliki, agar membantu perekonomian warga dengan cara membuka usaha kecil dari produk lokal yang sudah ada di desa tersebut. Desa tersebut juga memiliki lokasi indah untuk dikembangkan tempat-tempat seperti taman bunga, taman bermain, gubuk baca, yang sangat membantu kegiatan KKN kami. Kami pun ikut membantu perkembangan lokasi-lokasi komersial yang sudah ada di desa tersebut. Taman Bunga merupakan sasaran utama program kerja kita. Kami tahu efek pengembangan taman adalah membuat lebih indah suasana desa, menjadi ikon desa, dan bisa sebagai tempat peretemuan antar warga desa. Pada akhirnya taman bunga, taman bermain, gubuk baca lebih hidup dengan adanya program kerja kita. Taman-taman di desa tersebut akhirnya menjadi tempat komersial yang sangat membantu perekonomian warga desa setempat. Jadi program kerja kita sangat membantu merubah pola pikir warga desa untuk meningkatkan perekonomian dan lokasi-lokasi menjadi lebih komersial, dan desa tersebut dapat mewujudkan impian desa tersebut menjadi Desa Wisata.
\end{abstract}

Kata kunci: Desa Wisata, Pemberdayaan, Ekonomi, Gubuk Baca, local

\begin{abstract}
The real work lecture of a community service that we did was in Pagerngumbuk Village, Wonoayu District. A very suitable location to support our Community Service Program activities to develop the potential of the Village. With the hidden potential in the village we will explore the village's potential more by way of socializing traditional games to the children of the villagers. With the traditional game, this village will become a tourist village with the concept of developing the mindset of children, besides that it can also develop the economy of local residents. By conducting counseling, training, and socialization about the potential of tourism villages. We invite the villagers to be more active and more aware of the potential of the village they have, in order to help the local economy by opening a small business from local products that already exist in the village. The village also has beautiful locations to develop such places as flower gardens, playgrounds, reading huts, which greatly help our community service activities. We also help the development of commercial locations that already exist in the village. Flower Garden is the main target of our work program. We know the effect of developing the park is to make the village more beautiful, become an icon of the village, and can be a meeting place between villagers. In the end
\end{abstract}


the flower garden, playground, reading hut is more alive with our work program. The parks in the village eventually became commercial places that greatly helped the economy of the local villagers. So, our work program really helps change the mindset of villagers to improve the economy and locations to be more commercial, and the village can realize the dream of the village into a Tourism Village.

Keywords: Tourism Village, Empowerment, Economy, Reading Hut, local

\section{PENDAHULUAN}

Kuliah Kerja Nyata merupakan proses pembelajaran bagi Tim Pengabdian yang dikembangkan melalui kegiatan pengabdian kepada masyarakat dalam berbagai segi kehidupan bermasyarakat. Pelaksanaan KKN ditujukan untuk mendapatkan beberapa perhatian utama di desa Pegerngumbuk Dusun Bendet, Wonoayu, Sidoarjo, diantaranya adalah wisata edukasi bagi anak anak untuk mengenalkan permainan tradisional yang dapat menarik minat pengunjung untuk dating ke tempat itu, sehingga memiliki nilai ekonomi. Untuk menunjang hal tersebut kami melakukan kegiatan penghijauan lingkungan sekitar untuk meningkatkan keindahan lingkungan itu dan pengembangan ekonomi, juga membangun semangat warga desa tersebut untuk meningkatkan kembali ekonomi warga desa sehingga dapat mengoptimalisasi dan meningkatkan potensi lingkungan yang bernilai ekonomi di desa Pegerngumbuk, Desa Pager ngumbuk yang terletak di kecamatan Wonoayu, Sidoarjo yang berjarak $24,6 \mathrm{~km}$ dari Universitas Bhayangkara Surabaya.

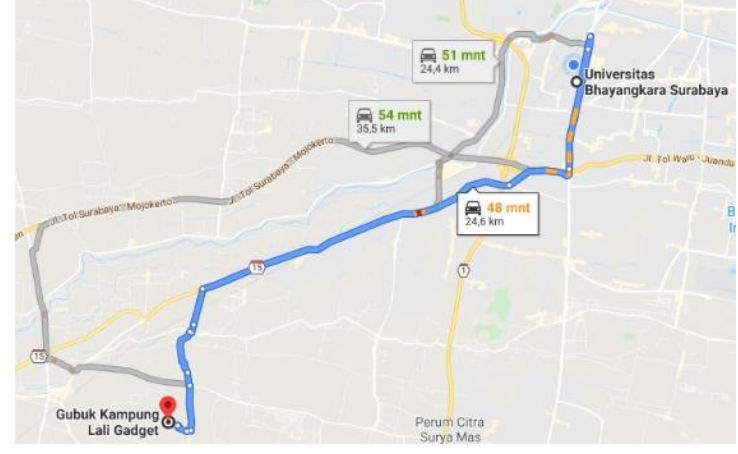

Permainan tradisional sangatlah populer sebelum teknologi masuk ke Indonesia. Dahulu, anak-anak bermain dengan menggunakan alat yang seadanya. Namun kini, mereka sudah bermain dengan permainan-permainan berbasis teknologi yang berasal dari luar negeri dan mulai meninggalkan mainan tradisional. Seiring dengan perubahan zaman, Permainan tradisional perlahanlahan mulai terlupakan oleh anak-anak Indonesia. Bahkan, tidak sedikit dari mereka yang sama sekali belum mengenal permainan tradisional. Permainan tradisional sesungguhnya memiliki banyak manfaat bagi anakanak. Selain tidak mengeluarkan banyak biaya dan bias juga untuk menyehatkan badan bias juga permainan tradisional adalah sebagai olahragah karena semua permainan mengunakan gerak badan yang ekstra, permainan tradisional sebenarnya sangat baik untuk melatih fisik dan mental anak. Secara tidak langsung, anak akan dirangsang kreatifitas, ketangkasan, jiwa kepemimpinan, kecerdasan, dan keluasan wawasannya melalui permainan tradisional.

Para psikolog menilai bahwa sesungguhnya mainan tradisional mampu membentuk motorik anak, baik kasar maupun halus. Salah satu permainan yang mampu membentuk motorik anak adalah dakon. Motorik halus lebih digunakan dalam 2 permainan ini. Pada permainan ini pemain dituntut untuk memegang biji secara utuh sembari meletakkannya satu-satu di kotakkannya dengan satu tangan.1 Selain itu, permainan tradisional juga dapat melatih kemampuan sosial para pemainnya. Inilah yang membedakan permainan tradisional dengan permainan modern. Pada umumnya, mainan tradisional adalah permainan yang membutuhkan lebih dari satu pemain, Hal ini sangat berbeda dengan pola permainan modern. Kemampuan sosial anak tidak 
terlalu dipentingkan dalam permainan modern ini, malah cenderung diabaikan karena pada umumnya mainan modern berbentuk permainan individual di mana anak dapat bermain sendiri tanpa kehadiran teman-temannya. Sekalipun dimainkan oleh dua anak, kemampuan interaksi anak dengan temannya tidak terlalu terlihat. Pada dasarnya sang anak terfokus pada permainan yang ada di hadapannya. Mainan modern cenderung bersifat agresif, sehingga tidak mustahil anak bersifat agresif karena pengaruh dari mainan ini. Meskipun permainan tradisional sudah jarang ditemukan, masih ada beberapa anak Indonesia di daerah-daerah terpencil yang memainkan permainan ini di kota besar seperti sidoarjo, masih ada anak yang bermain permainan tradisional. Bahkan, permainan tradisional juga digunakan oleh para psikolog sebagai terapi pengembangan kecerdasan anak

Salah satu ciri dari desa yang masih berada dalam tingkatan Desa Berpotensi untuk tingkatan desa wisata adalah masih adanya masyarakat yang kurang memahami potensi yang berada di desanya. Perlu adanya pemahaman bagi warga untuk memahami manfaat pengembangan desa sebagai desa wisata yang mana mungkin tidak semua akan menerima pada awalnya. Di desa pagerngmbuk ini sendiri terdapat kelompok KLG ( Kampung Lali Gadget ) yang mengusung tema pengembangan desa wisata berbasis permainan tradisional yang dkhusukan untuk anak-anak, selain permainan tradisional banyak kegiatan/ edukasi yang dilakukan untuk menarik animo masyarakat dari luar untuk mengikuti salah satu event yang diadakan oleh KLG.

Oleh karena itulah, perlu adanya penjelasan atau penyampaian mengenai manfaat pengembangan permainan tradisional sebagai desa wisata yang nantinya akan dirasakan oleh warga local. Manfaat tersebut juga perlu dijelaskan dalam jangka pendeknya, jangka panjangnya hingga beberapa desa yang bisa dijadikan percontohan sebagai desa wisata yang sukses. Berikut antara lain manfaat tersebut adalah:

1. Tingkat Hidup Masyarakat Maju
2. Meningkatnya perekonomian warga local

3. Menciptakan home industry sekitar desa wisata

4. Promosi produk local yang semakin berkembang

\section{KAJIAN LITERATUR}

Desa wisata adalah suatu bentuk integrase antara atraksi, akomodasi, dan fasilitas pendukung yang disajikan dalam struktur kehidupan masyarakat yang menyatu dengan tata cara dan tradisi yang berlaku (Nuryanti,Wiendu 1993) berbagai potensi yang ada di desa harus di maksimalkan untuk mendapatkan hasil yang positif bagi warga local yang berada di sekitar lokasi desa. Menurut Conyers dkk dalam Munir (2002:23) mendefinisikan perencanaan sebagai proses yang berkesinambungan yang mencakup keputusan- keputusan (kebijakan) atau pilihan-pilihan berbagai alternatif penggunaan sumberdaya untuk mencapai tujuan-tujuan tertentu pada masa yang akan datang jadi pembentukan desa wisata perlu adanya sebuah perencanaan yang sangat matang dan terarah agar program desa wisata bisa berjalan dengan baik,selain itu warga local dan perangkat desa juga perlu adanya sinergi untuk melakukan tugasnya masingmasing dalam perencanaan tersebut.

Desa wisata, sebagai salah satu bentuk dari pariwisata pedesaan dapat memberikan banyak manfaat kepada upaya pengembangan berbagai sumber daya yang dimiliki oleh daerah pedesaan (Sugiarti,2008). Berbagai potensi tersebut dapat menjadi daya tarik wisata yang dapat memberikan pengalaman autentik kepada wisatawan dan sekaligus memberikan Kesempatan kepada masyarakat setempat untuk mendapatkan penghasilan tambahan melalui pariwisata. Pengembangan desa wisata dengan demikian dapat menjadi salah-satu upaya untuk menumbuhkan potensi kewirausahaan lokal, mendiversifikasi produk pariwisata, menopang perekonomian masyarakat setempat, serta merevitalisasi budaya lokal. Dengan adanya konsep yang jelas yang diusung oleh desa wisata maka akan 
didapatkan sebuah potensi yang bisa menghasilkan nilai perekonomian dan nilai social bagi warga local atau pun wisatawan yang datang.

$$
\text { Dalam hubungannya dengan }
$$

pembangunan ekonomi wilayah, pengembangan desa wisata disinyalir dapat mengatasi urbanisasi dan mendorong perekonomian pedesaan. Di samping itu pariwisata pedesaan berperan dalam meningkatkan kualitas hidup masyarakat pedesaan. Sebagai salah-satu bentuk pariwisata alternatif, desa wisata dapat menjadi alat yang potensial untuk menunjang pembangunan lingkungan yang berkesinambungan (Oppermann, 1996; Crotts dan Holland,1993). Selain menimbulkan dampak positif, pengembangan desa wisata yang kurang terkontrol juga bisa memunculkan dampak negatif terhadap lingkungan pedesaan. Dampak tersebut antara lain adalah meningkatnya tekanan terhadap lingkungan akibat pembangunan infrastruktur dan pengadaan fasilitas untuk menunjang kegiatan desa wisata(Page and Gertz,1997).

\section{METODE PELAKSANAAN}

Dari hasil pertemuan dan wawancara antara team pengabdian, warga lokal beserta perangkat desa dan ketua kelompok Kampung Lali gadget di balai desa Pagerngumbuk. Dihasilkan beberapa kegiatan yang bisa membantu mendorong desa wisata KLG menjadi lebih asri dan indah. Upaya-upaya yang kita lakukan adalah antara lain Pengembangan taman dan lingkungan desa KLG, Membantu perniagaan dilokasi wisata untuk meningkatkan perekonomian masyarakat sekitar ,Kerja bakti pembersihan taman dengan masyarakat sekitar ,Penyuluhan tentang bahayanya gadget untuk anak-anak dengan metode nonton film yang diselipi beberapa hal yang berbahaya tentang gadget dengan menjadikan permainan tradisional sebagai solusi untuk memerangi penggunaan gadget yang berlebihan untuk anak-anak. Selain sebagai produk wisata andalan di KLG permainan tradisional juga bisa sebagai alat untuk mencerdaskan anak-anak warga local.

Pembuatan taman berguna untuk menghias lingkungan sekitar untuk memperindah lingkungan agar terciptanya lingkungan yang asri untuk membantu mensukseskan desa wisata KLG yang telah di canangkan oleh perangkat desa dan KLG sendiri. Pengecatan jalan paving dengan gambar permainan tradisional untuk menambah lingkungan biar kelihatan indah. Bahan-bahan yang disiapkan adalah: Ban Bekas, Tanaman, Cat, pupuk, paku, tanah, batu hias dan botol bekas. Dengan memanfaatkan barang-barang bekas sebagai media untuk pembuatan taman juga mengurangi sampah disekitar lokasi desa wisata.

Dengan tema meningkatkan perkonomian warga local lewat permainan tradisional, maka kita mendorong untuk masyakat sekitar untuk mandiri bisa meningkatkan ekonomi mereka dengan cara ikut berpartisipasi ketika ada event dengan membuka suatu lapak berdagang produk lokal. Selain itu kita juga membantu tenda yang digunakan untuk perlengkapan berdagang di sekitar lokasi event KLG.

Kerja bakti dilakukan disekitar kampung lali gadget dimana pusat event akan dilakukan, berbagai macam kegiatan dilaksanakan disana mulai pembersihan area lingkungan sekitar desa wisata atau KLG, pemasangan alat perlengkapan event seperti papan pengumuman, banner dll. Selain team pengabdian kerja bakti juga dibantu oleh kelompok karang taruna dan warga, dengan sebuah gotong royong ini ada semangat bagi warga local untuk meningkatkan desa wisata mereka yang telah dirintis.

Konsep yang diusung di Desa wisata Kampung lali gadget adalah mengurangi pemakaian gadget untuk anak-anak disamping itu Kampung lali gadget juga mengusung tema mengenalkan permainan tradisional yang telah lama hilang. Dengan metode nonton bareng film documenter disini anak-anak akan memperhatikan yang akan disampaikan beberapa bahaya penggunaan gadget pada anak-anak. Saat ini permainan 
tradisional sudah mulai tergerus oleh jaman oleh sebab itu Kampung lali gadget berupaya untuk menjadikan permainan tradisional untuk bisa menjadi sebuah nilai wisata bagi para pengunjung yang notabane nya penduduk kota besar dengan perkembangan anak-anaknya yang selalu di isi dengan gadget.

Rencana kegiatan yang dilaksnakan harus ada kordinasi pihak terkait dengan para perangkat daerah di lingkungan sekitar berikut adalah alur bagan kordinasi yang dilakukan

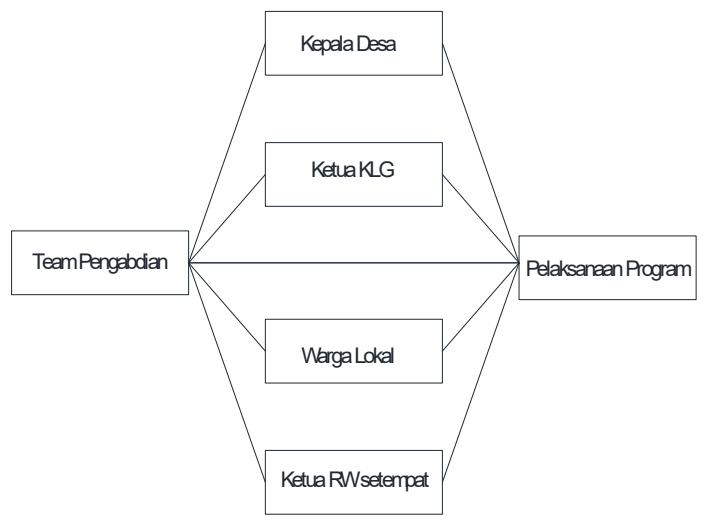

Diaram 1. Alur kordinasi

\section{HASIL DAN PEMBAHASAN}

Desa wisata merupakan salah satu bentuk Wisata Pedesaan. Wisata pedesaan merupakan perjalanan yang berorientasi menikmati suasana kehidupan pedesaan, menghormati serta memperoleh nilai tambah hidup dari budaya dan tradisi masyarakat setempat serta lingkungan alam, juga meningkatkan kesejahteraan masyarakat setempat. Kehidupan sehari-hari masyarakat setempat dan lingkungannya merupakan obyek dan daya tarik wisata. Ada berbagai upaya yang dilakukan team pengabdian untuk meningkatkan potensi desa wisata di KLG.

Mengembangkan taman dan lingkungan di KLG untuk menarik wisatawan agar berkunjung ke desa wisata tidak bisa dipungkiri bahwa lingkungan menjadi factor sendiri untuk meningkatkan kunjungan untuk itu team pengabdian melakukan pengembangan disektor lingkungan KLG dengan pembuatan taman yang sebelum nya belum ada, diharapkan dengan adanya taman ini bisa membuat para pengunjung ataupun wisatawan bisa menikmati pemandangan yang lebih indah.

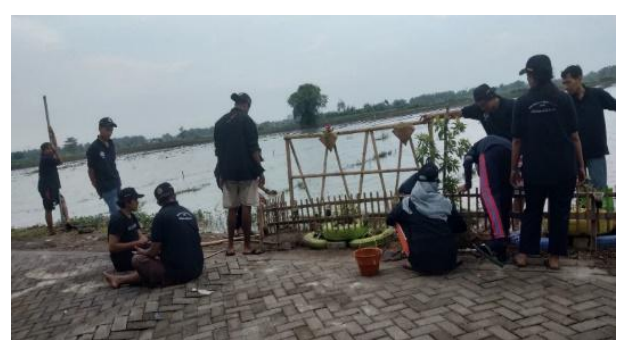

Gambar 1 a. Pembuatan Taman

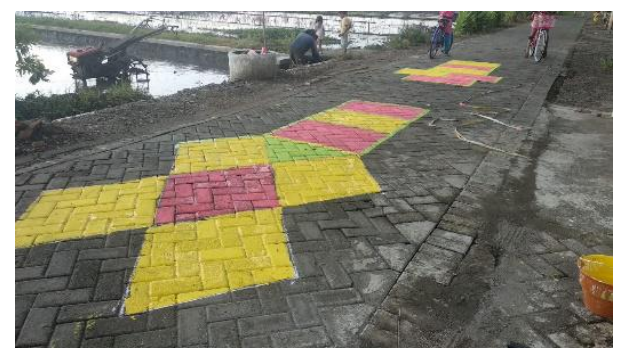

Gambar 1.b Pengecatan Jalan paving

Selain untuk menjadikan desa wisata semakin berkembang kita juga mendorong masyarakat untuk meningkatkan ekonomi dengan melakukan kegiatan ekonomi salah satunya adalah berdagang produk local yang dilakukan disekitar lingkungan KLG. Disisi lain dengan adanya aktivitas ini maka perekonomian warga masyrakat local akan bertambah satunya adalah berdagang produk local yang dilakukan disekitar lingkungan klg Disisi lain dengan adanya aktivitas ini maka perekonomian warga masyarakat local juga akan bertambah.

Selain mendorong kegiatan ekonomi kita juga ikut serta membantu warga local untuk melakukan kerja bakti untuk membersihkan lingkungan sekitar desa wisata dengan diadakan kerja bakti yang dilakukan oleh team pegabdian dan warga local diharapkan linkungan sekitar menjadi lebih bersih membuat wisatawan mempunyai kesan bahwa lingkungan sekitar bersih. Selain membersihkan lingkungan kita juga membantu KLG untuk mempesiapkan event yang akan berjalan. 


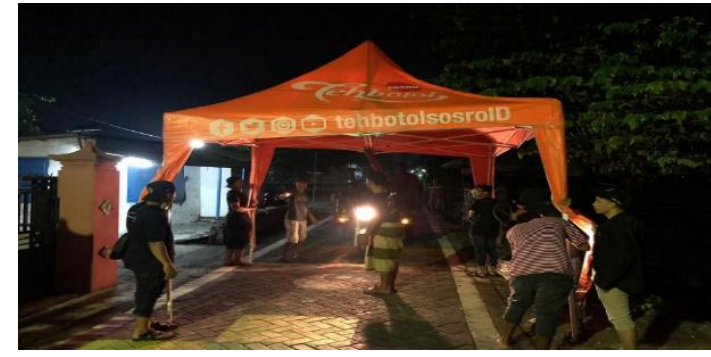

Gambar 2. Pemasangan Tenda untuk lokasi berdagang

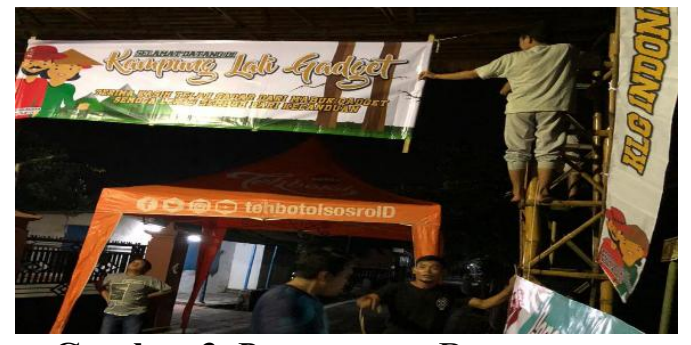

Gambar 3 Pemasangan Banner event

Melakukan sosialisasi kepada anakanak warga sekitar tentang bahanya pengunaan gadget pada anak-anak pada penggunaan yang berlebihan, permainan tradisional dipakai untuk media pembelajaran untuk meningkatkan kecerdasan anak dan kerjasama antar individu bisa terbangun. Untuk sosialisasi kali ini kita menggunakan nonton bareng film documenter yang bersifat memotivasi dengan menyelipkan diantara kegiatan ini anak-anak diharapkan bisa mengerti dan memperhatikan nilai nilai yang disampaikan. Berikut adalah bagan tujuan dari kegiatan diatas:

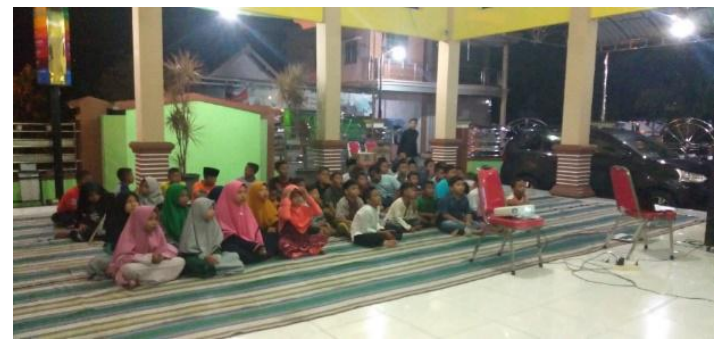

Gambar 4. Sosialisai kepada Anak-anak

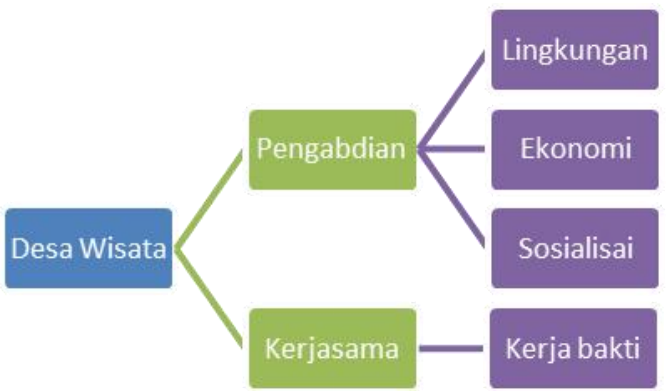

Diagram 2 . Bagan tujuan dari semua kegiatan

Semua kegiatan pegabdian yang dilakukan adalah untuk mengembangkan potensi desa wisata dengan mengedepankan konsep permainan tradisional yang menjadi ikon utama. Karena permainan tradisional yang mulai hilang ini akan menjadi icon utaman untuk pengembangan desa wisata dengan banyaknya pengunjung maka perekonomian warga sekitar akan tumbuh.

\section{KESIMPULAN DAN SARAN Kesimpulan}

Keberadaan desa wisata telah memberikan dampak positif kepada masyarakatnya. Perekonomian masyarakat mengalami peningkatan, sejak Dusun Pagerngumbuk berkembang menjadi desa wisata. Dengan dijadikannya Dusun Pagerngumbuk sebagai desa wisata juga berperan dalam menciptakan keakraban dan kerukunan antar warga. Gotong-royong, kerukunan, dan silturahmi warga semakin erat dengan banyaknya kegiatan di desa wisata. Masyarakat semakin sadar akan budaya dan terus menjaga dan melestarikan kesenian-kesenian tradisional terutama permainan tradisional untuk anak anak di desa Pagerngumbuk. Dampak yang dimunculkan dari fenomena perubahan yang terjadi di masyarakat Dusun Pagerngumbuk tidak hanya dari segi positif, namun terdapat sedikit dampak negatif yang ditimbulkan. Namun, bagi generasi muda yang menanggapi kemajuan teknologi dengan positif justru menggunakan kemajuan teknologi untuk mengembangkan bisnis dan eksistensi Desa Wisata Pagerngumbuk. 


\section{Saran}

Kita sebagai generasi milineal harusnya bisa mengembangkan permainan tradisional dilingkungan sekitar kita tidak terbatas hanya di lingkungan desa wisata. Sinergi dan kerjasama antar elemen masyarakat sangat diperlukan untuk mengembangkan desa wisata Kampung lali gadget yang mempunyai konsep permainan tradisional yan memiliki fungsi untuk meningkatkan ekonomi masyrakat local dan untuk mencerdaskan anak-anak warga local.

\section{UCAPAN TERIMAKASIH}

Kegiatan KKN Tematik Tahun 2020 terselenggara oleh universitas bhayangkara Surabaya yang telah memberi fasilitas mahasiswa peserta KKN didesa pagerngmubuk kecamatan wonoayu kabupaten sidoarjo, kepala desa pagerngumbuk yang telah mengizinkan kami untuk melakukan pengabdian kami kepada masyarakat.

Kepada Bapak RW setempat yang telah memberikan tempat dan pengarahan ketika melakukan program agar berjalan dengan baik, serta ketua kampung lali gadget yang selalu melakukan bimbingan kepada team pengabdian agar program yang direncanakan bisa berjalan dengan lancar. Kepada DPL bapak Tri wardoyo,kepada teman-teman anggota kelompok 41 : surya ( sipil ),rohman (sipil),sukadi (sipil),yessy ( sipil ), fitria (sipil),kiki ( sipil ), riskia ( sipil ), firdan ( sipil ), Kris (sipil ), adi (elektro ),bayu (elektro ),zulfi (elektro ), affan (elektro ),jeto ( social ), dan ivan ( social )

\section{REFERENSI}

Daur Ulang. "Cara Membuat Taman Dari Ban Bekas Yang Mudah Dan

Sederhana". 10

Januari2020.(http://www.daurulang.com/2020/02/kreasi-tamandari-ban.html)

Bibit Bunga "Cara Membuat Pot Bunga Dari Botol Bekas"..10 Jnuari 2020. (https://bibitbunga.com/caramembuat-pot-bunga-dari-botolbekas/)

\author{
Limakaki.com "Kampung Bekelir, Destinasi \\ Wisata Baru di Kota Tangerang yang \\ Sedang Hits".10 januari 2020. \\ (https://limakaki.com/kampung- \\ bekelir.html) \\ Berdesa.com " definisi-desa-menurut- \\ berbagai-ahli". 14 Maret 2020. ( \\ http://www.berdesa.com/definisi- \\ desa-menurut-berbagai-ahli//)
}


